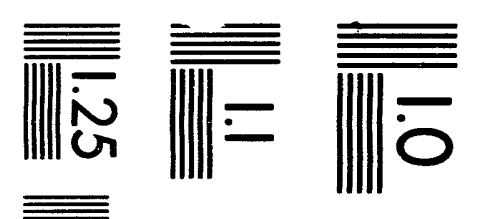

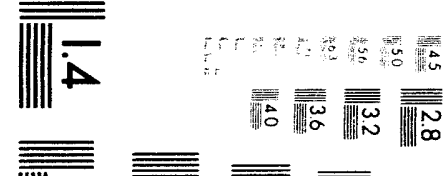

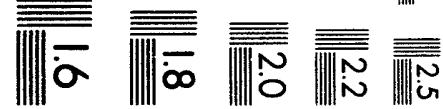





\section{APPLICATION OF DIVERTOR CRYOPUMPING TO H-MODE DENSITY CONTROL IN DIII-D}

by

M.A. MAHDAVI, J.R. FERRON, A.W. HYATT, R.J. La HAYE

G.L. LAUGHON, M. LEH, R. MAINGI, ${ }^{\dagger}$ M.M. MENON, ${ }^{\dagger}$

P.K. MIODUSZEWSKI, ${ }^{\dagger}$ K.M. SCHUABEL, M.J. SCHAFFER, D.P. SCHISSEL, J.T. SCOVILLE, J.P. SMITH, R.D. STAMBAUGH, and Mi. WADE ${ }^{\dagger}$

This is a preprint of a paper to be presented at the 15th IEEE/NPSS Symposium on Fusion Engineering, October 11-15, 1993, in Hyannis, Massachusetts, and to be printed in the Proceedings.

Work supported by U.S. Department of Energy Contract DE-AC03-89ER51114

† Oak Ridge National Laboratory.

GENERAL ATOMICS PROJECT 3466

NOVEMBER 1993

\section{GENERAL ATOMICS}

Pring 


\title{
APPLICATION OF DIVERTOR CRYOPUMPING TO H-MODE DENSITY CONTROL IN DIII-D.
}

\author{
M.A. Mahdavi, J.R. Ferron, A.W. Hyatt, R.J. La Haye, G.L. Laughon, M. Leh, K.M. Schaubel, \\ M.J. Schaffer, D.P. Schissel, J.T. Scoville, J.P. Smith, and R.D. Stambaugh \\ General Atomics \\ P.0. Box 85608, San Diego, Cílifornia 92186-9784 \\ R. Maingi, M.M. Menon, and P.K. Mioduszewski, M. Wade \\ Oak Ridge National Laboratory \\ P.O. Box 2009, Oak Ridge, Tennessee 37831
}

\section{ABSTRACT}

In this paper we describe the method and the results of experiments where a unique in-vessel cryopumpbaffle system was used to control density of H-mode plasmas. We were able to independently regulate current and density of ELMing $\mathrm{H}$-mode plasmas, each over a range of factor two, and measure the H-mode confinement scaling with plasma density and current. With a modest pumping speed of $\approx 40 \mathrm{kl} / \mathrm{s}$, particle exhaust rates as high as $2 \times 10^{22}$ atom $/ \mathrm{s}^{-1}$ have been observed.

\section{INTRODUCTION}

Development of an effective particle control technique is essential for the viability of a tokamak fusion reactor. In burning plasmas, particle control is primarily needed for helium ash exhaust and impurity control. In present devices, particle control provides the experimental flexibility necessary for systematic investigations of energy and particle transport and if current drive.

In typical $\mathrm{H}$-mode plasmas, the good confinement regime of tokamaks, the plasma density increases rapidly after the transition to the H-mode. In DIII-D, the plasma density eventually saturates at a level proportional to the plasms current, $n_{e}\left(10^{3} \mathrm{~cm}^{-13}\right) \approx 6 \times I_{P}$ (MA). This co-linearity prevents an independent determination of scaling of the plasma confinement with $n_{e}$ and $I_{p}$. Furthermore, the ultimate density reached in $H$-mode is too high for planned DIII-D current drive experiments. In the past, helium glow and other wall conditioning techniques have been used successfully in controlling density in L-mode plasmas [1]; however, similar efforts on H-mode plasmas have produced only small effects.

The DIII-D advanced divertor system [2] was designed and built with the primary goal of particle control in $\mathrm{H}$-mode plasmas. The system consists of an integrated divertor bias electrode, a baflle, and an in-vessel cryopump. The combination of the bias ring electrode, the baftle, and the vessel wall form the cryopump plenum (Fig. 1). A toroidal gap separating the bias ring from the divertor floor defines a short duct to the pumping plenum. Biasing applications [3] include enhancement and regulation of particle flux into the pumping plenum. Results of biasing studies and bafle pressure measurements in the absence of pumping have been reported earlier $[3,4,5]$. In this paper we describe the method and results of $\mathrm{H}$-mode density control experiments using the in-vessel cryopump - baffle system, in the absence of biasing. Simultaneous pumping and biasing experiments have not yet been done.

\section{DIII-D PUMPED DIVERTOR CONCEPT}

A necessary condition for active density control is a capability to exhaust particles at a rate faster than the external particle sources. The dominant external particle source in DIII-D plasmas is the neutral beam injection system, which typically deposits 20 Torr $\ell / s\left(\sim 1.5 \times 10^{21}\right.$ particles per second) into the core plasma. In addition, depending on the condition of the graphite ressel and divertor armor, the vessel walls can pump awrey or add particles at rates as high as $100 \mathrm{Torr} / \mathrm{s}$. A design objective of the DIII-D pumped divertor project was to achieve a particle exhaust rate greater than or equal to the neutral beam injection source.

In earlier generation closed divertor devices for the purpose of particle and impurity control, the entire volume of the divertor plasma was pumped. This approsch, as the following discussion will show, required very large pumping speeds of the order of several hundred thousand $2 / s$. The pumped divertor concept described here, specifically designed for the open geometry of the DIII-D divertor plasmas, is effective with an order of magnitude lower pumping speed. In this scheme, a fraction of the divertor recycling neutrals is scooped of directly by placing the divertor recycling sone at the opening of a toroidal pumping plenum. Detailed description of the pumping concept and optimiration studies can be found in earlier publications [6-8] Here we present a semi-quantitative discussion on how the concept works.

The pumping plenum pressure and the particle exhaust rate can be estimated by equating particle flux into the plenum, $\Gamma_{N}$, to the sum of the pump exhaust and the rate of particles escaping back into the plasma, i.e. $\Gamma_{N}=P(C+S)$, where $P$ is the pressure, $C$ is the

Mamuecript roceived November 10, 1093. This is a report of work moneared by the U.S. Department of Energy under Contract Now. DE-ACO3-89ER51114 and DE-AC05-84OR21400. 

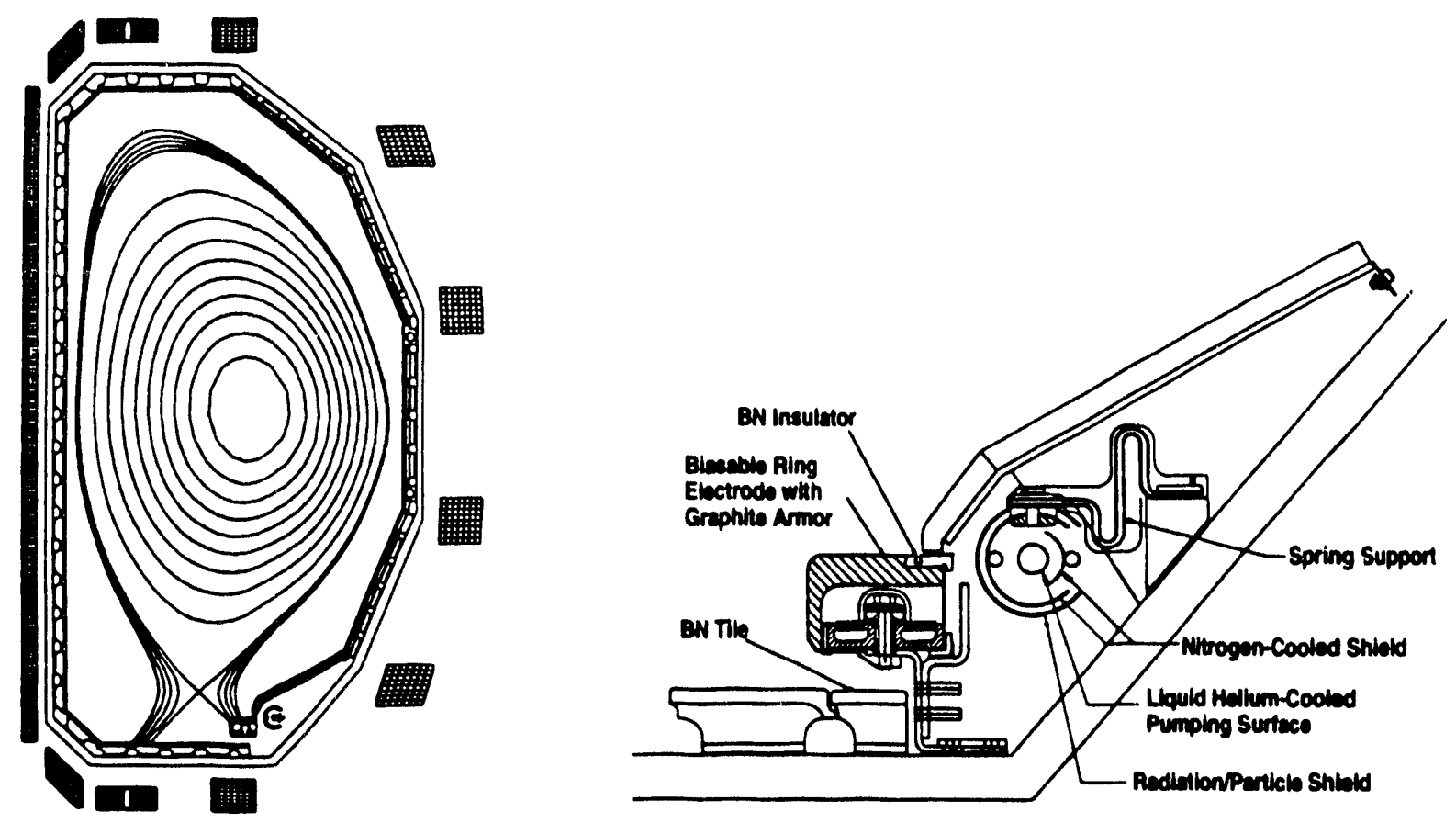

Fig. 1. A cross sectional view of the DIII-D advanced divertor configuration, showing the bias ring and the cryopump. The gap between the bias ring and the vessel floor armor defines the opening to the pumping plenum.

aperture conductance and $S$ is the pumping speed. Here for the sake of simplicity we assume that $\Gamma_{N}$ is independent of $S$. Then, this relationship shows that the pump exhaust reaches $60 \%$ of the incident flux when $S=C$. Since the exhaust rate increases slowly with gap $S>C$, which incurs greater engineering complexities and cost, a pumping speed equal to the conductance of the duct was selected as the design goal.

The quantity $\Gamma_{N}$ is a function of the divertor plasma parameters and the plenum aperture conductance. For a given divertor plasma, initially $\Gamma_{N}$ increases rapidly with increasing height of the toroidal duct defining the pumping plenum aperture. However, $\Gamma_{N}$ is nearly at its maximum value when the duct height is equal to or greater than either the neutral particle mean free path or the width of the SOL. Any further increase in the duct height beyond this point increases the required pumping speed without significantly increasing the exhaust rate.

Since it was anticipated that the most difficult density control conditions are in low collisionality plasmas, we selected a duct height of $\approx 3.5 \mathrm{~cm}$, equal to the divertor SOL width of typical DIII-D divertor plasmas. For this duct height, we estimate $\Gamma_{N}=100$ Torr $l / s$, roughly $10 \%$ of the divertor ion flux for a typical DIII-D divistor plasma. Thus the pump echaust rate $S \times P=\frac{1}{2} \Gamma_{N}=$ 50 Torr $\ell / \mathrm{s}$. Finally, given a duct length of $\approx 10 \mathrm{~cm}$, determined by biasing considerations, we arrive at a duct conductance and pumping speed of $50,000 \ell / \mathrm{s}$ which is then the pumping speed goul.

\section{DIVERTOR PUMP DESIGN AND CONSIDERATIONS}

The DIII-D vessel was designed to be compatible with either in-vessel or appendage pumps. As seen in Fig. 1, the vessel bottom is larger than the top to allow for installation of in vessel cryo- or getter-pumping. In addition, 24 high conductance pumping ports are available for either appendage or re-entrant pumps. In practice, since most of the designated pumping ports have been taken by valuable plasma diagnostics, the conceptual design effort was narrowed to getter and cryopumps. Because of the inaccessibility of an internal getter source, we only considered long life getters of the Tore-Supre type [8]. This type of pump relies on rejuvenation of a passivated gettering surface by overcoating the surface with only a very thin layer of titanium and then baking at high temperature. As a result, the getter wire would last much longer compared to the conventional thick layer method. However, measurements [9] showed that although the pumping speed of a surface rejuvenated in this fashion is nearly as good as a fresh coating, its particle throughput is greatly reduced and would not meet the DIII-D requirements.

Cryopumping is a well established technology and it has been successfully used in tokamak subsystems such as neutral beam heating drift ducts and as appendage vessel pumps. However, the DIII-D divertor cryopump is the first application of this technique inside a tokamak plasma chamber. Because of the adverse environment of the DIII-D plasma chamber, including disruptions, heat load, and baking cycles to $450^{\circ} \mathrm{C}$, the design of the cryopump posed a challenging engineering problem. 
A major concern in the conceptual design of the pump was the possibility of arcing between the cryogenic elements and the surrounding structure. During plasma disruptions, toroidal voltages of a few hundred volts are induced. Because of presence of ionizing radiation, a wide range of possible gas pressures ( 0.1 to $50 \mathrm{mT}$ Torr) and variable path lengths along the field lines, the arcing problem is analytically intractable and insulation along the field lines impractical. However, the induced voltage between the pump and the ressel could be reduced to a safe limit, for any combination of accessible path length and pressure, by either breaking the cryopanel into at least three toroidal segments, or by building an electrically toroidally continuous cryoloop that remains always near vessel potential. A segmented liquid helium pump would have required more ports, vacuum feedthroughs, and cryotransfer lines and connectors, which would have significantly reduced the system reliability. On the other hand a toroidally continuous structure, which was ultimately chosen, brings problems of its own. In particular, in a toroidally continuous structure, induced currents during the plasma startup and plasma disruptions significantly increase heat loads and forces on the cryoelements. Other difficult design issues include: thermomechanical stresses during vessel bake-out (up to $450^{\circ} \mathrm{C}$ ) and cryopump operation, and heat loads on the cryopanels due to thermal radiation, neutral particles, inductive heating, and plasma radiation.
Details of the system design, construction and testing can be found in earlier publications and proceedings of this conference [10-17]. The pumping speed of the installed system was measured during an applied pulsed heat load of $300 \mathrm{~W}$ in the absence of a plasma. At an ambient pressure of $5 \mathrm{mTorr}$, the pumping speed is approximately $40,000 \mathrm{l} / \mathrm{s}$.

\section{ACTIVE DENSITY CONTROL EXPERIMENTS}

The efficacy of divertor pumping was tested by observing the rate of density decay after moving the divertor strike point from an initial position, several SOL widths away from the opening to the pumping plenum, to its optimum pumping position. In general, divertor pumping is found to be more effective in L-mode than in $\mathrm{H}$-mode because of the comparatively broader and denser SOL of $L$-mode plasmas. Typically in L-mode plasmas the density decay time constant is $\$ 100 \mathrm{~ms}$, and densities as low as $3 \times 10^{12}$ have been obtained. In contrast, in ELMing $\mathrm{H}$-mode plasmas, the initial density decay time constant is typically $0.5 \mathrm{~s}$. In the remainder of this paper we will discuss only the results from ELMing $\mathrm{H}$-mode plasmas.

We used a combination of gas puffing and divertor pumping to control the plasma density. The pumping rate, as shown in Fig. 2, was controlled by magnetically adjusting the position of the divertor strike point relative to the pumping plenum aperture. To assure stability, the
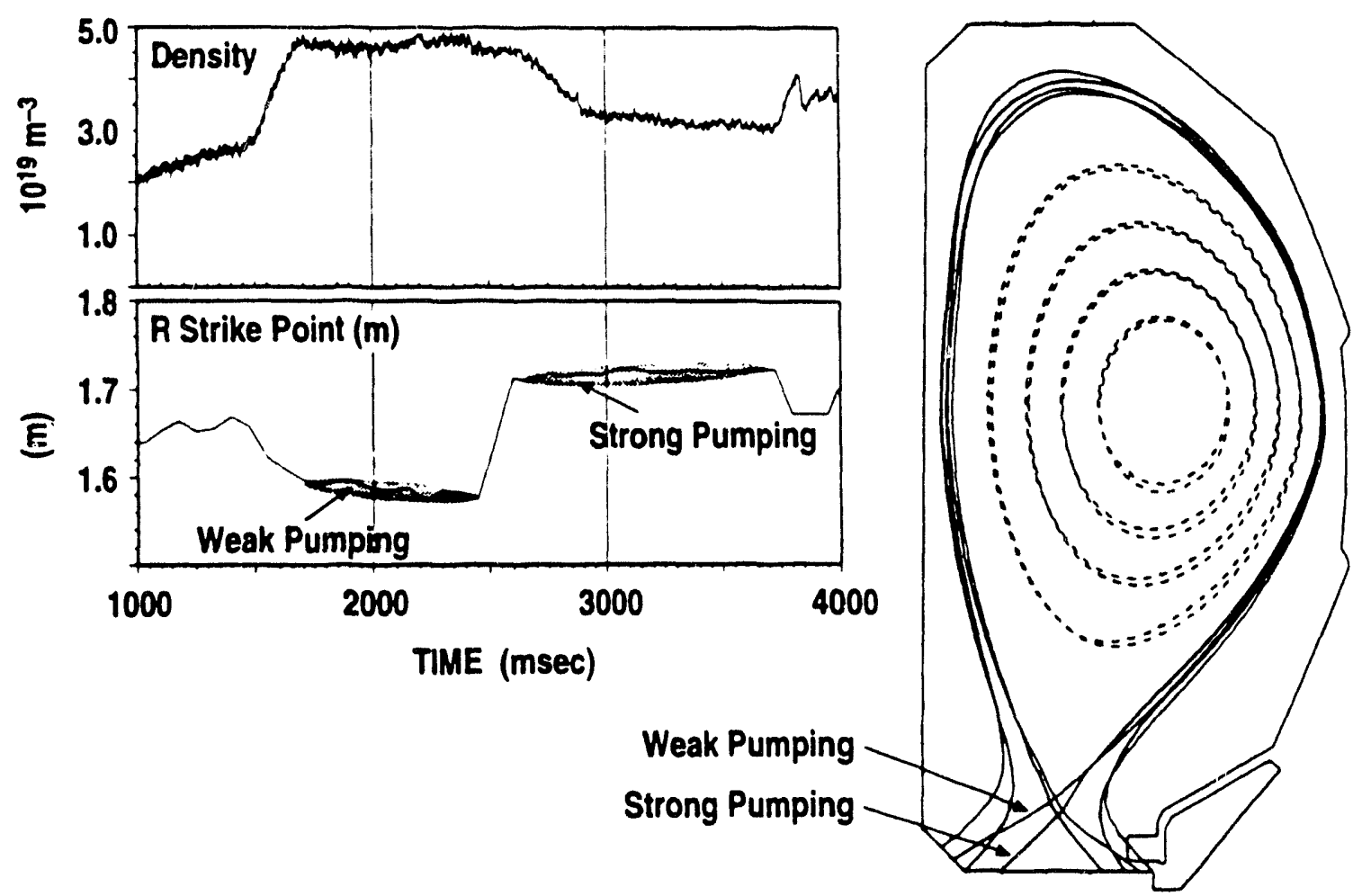

Frg 2. Magnetic control of pumping. The divertor pumping rate is controlled by adjusting the position of the divertor strike point relative to the pumping plenum aperture. 
feedback logic is programmed such that, normally, simultaneous gas puffing and divertor pumping are not atlowed. With this feedback system during $\mathrm{H}$-mode shots, the pump exhaust rate is typically a few tens of Torr $\ell / s$; when the divertor strike point is placed at its optimum pumping position with the density feed back active, exhaust rates as high as 200 Torrl/s are observed.

Using the above procedure, we were able to control the density and current of $\mathrm{H}$-mode plasmas independently. Fig. 3 displays examples of $\mathrm{H}$-mode plasmas where the plasma density was varied at constant $I_{p}$ over a range of a factor of two, and conversely, $I_{p}$ was varied at constant density over a range of a factor of two. Preliminary analysis suggests that $\mathrm{H}$-mode confinement is only a weak function of $n_{e}$ and increases almost linearly with $I_{p}$. Results of local and global transport studies in density controlled $\mathrm{H}$-mode plasmas will be presented in a separate paper [18].

In low to moderate powered $\mathrm{H}$-mode plasmas, with the divertor strike position placed at the optimum pumping position and the gas puff system desctivated, plasma density levels off at approximately $50 \%$ of the unpumped $\mathrm{H}$-mode value. In higher power plasmas a locked mode limits the lowest attainable $\mathrm{H}-$ mode density. Fig. 4 shows the growth of rotating a 2/1 Mirnow mode which slows down and locks. After the mode locks, the plasma reverts back to L-mode, as indicated by a rapid drop in $\beta_{N}$ $\left[\beta_{N} \equiv \beta\left(\frac{a \times B_{x}}{l_{P}}\right)\right]$ and plasma density.
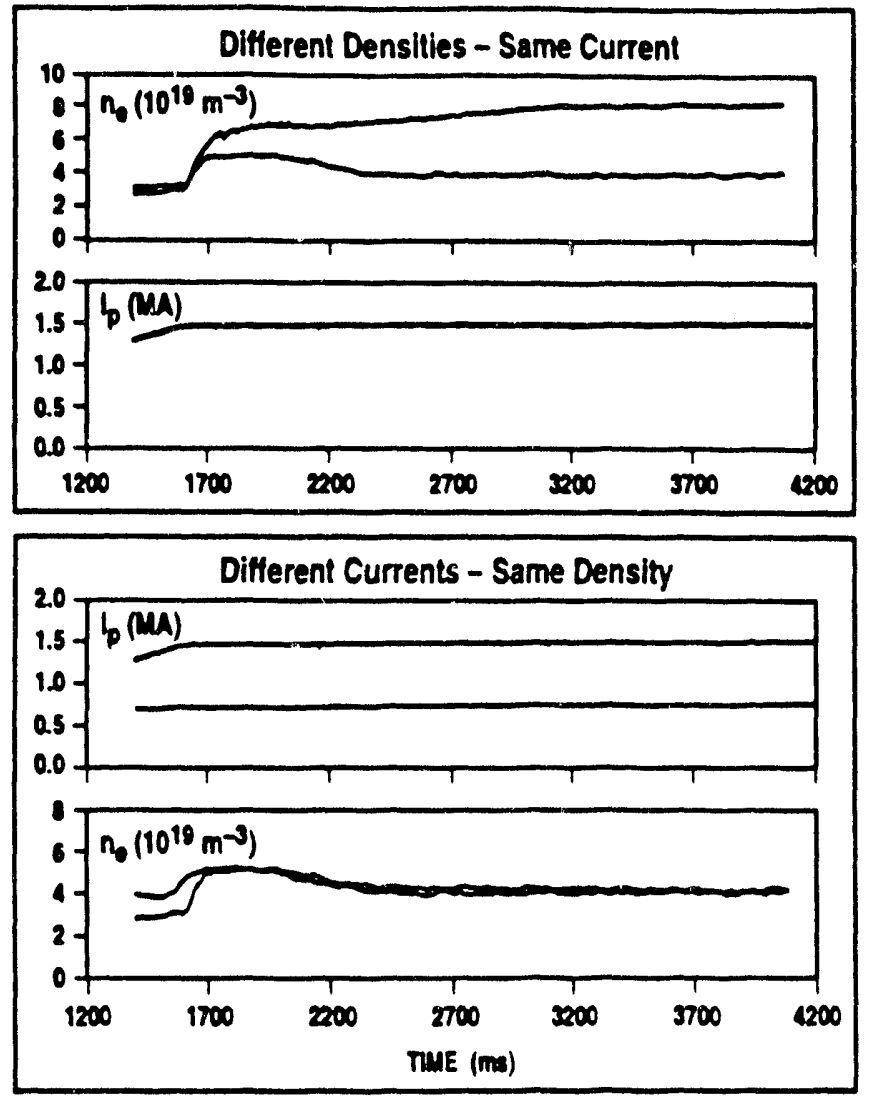

FiG. 3. Example of density regulated $\mathrm{H}$-mode plasmas.

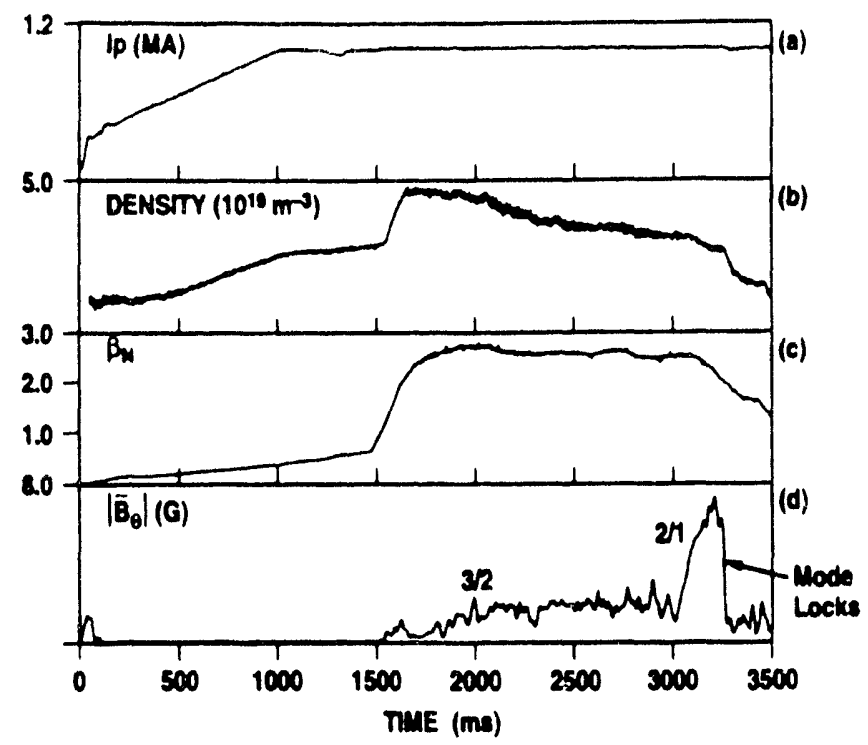

Fig. 4. (a) Plasme current, (b) line average electron density, (c) $\beta_{N} \equiv B\left(I / a B_{T}\right)^{-1}$, (d) magnetic fluctustions. The growth and locking of a 2/1 Minov mode limits the lowest attainable $\mathrm{H}$-mode density in plasmas with moderate to high heating power.

\section{ROLE OF THE WALL ON PARTICLE BALANCE}

Normally in DIII-D plasmas, the graphite vessel walls (here by wall we mean the divertor target plates and the exposed area of the vessel armor together), behave as a strong particle sink. This is demonstrated in Fig. 5, Shot 1 where in the absence of significant pumping, plasma particles account for only $10 \%$ of the injected cold gas and NBI particles. By the end of this shot, the wall particle inventory, as deduced from the difference between the known particle sources and sinks, has increased by nearly 150 Torre. Based on this observation one might expect that the graphite wall pumping would work in parallel with the divertor pump in reducing the plame density. The experimental data show that, on the contrary, the wall can work against the pump. This is demonstrated in Fig. 5, Shots 2 and 3, where after the divertor pump was activated at $t \simeq 1600 \mathrm{~ms}$, the wall behaves as a particle source. This surprising result is understood by noting that pumping reduces the ion flux to the divertor target without significantly affecting the heat flux, thus breaking the previously existing particle balance between the target and the plasma. This process is similar to the sudden density rise after the $L$ to $\mathrm{H}$-mode transition $[19,20]$ where the rate of density rise initially is much greater than the external particle sources.

In the shot shown in Fig. 5, Shot 2, by the end of the shot the wall particle inventory has increased only slightly whereas, by the end of the the shot shown in Fig. 5, Shot 3, there is a large particle deficit. The 
Shot 1
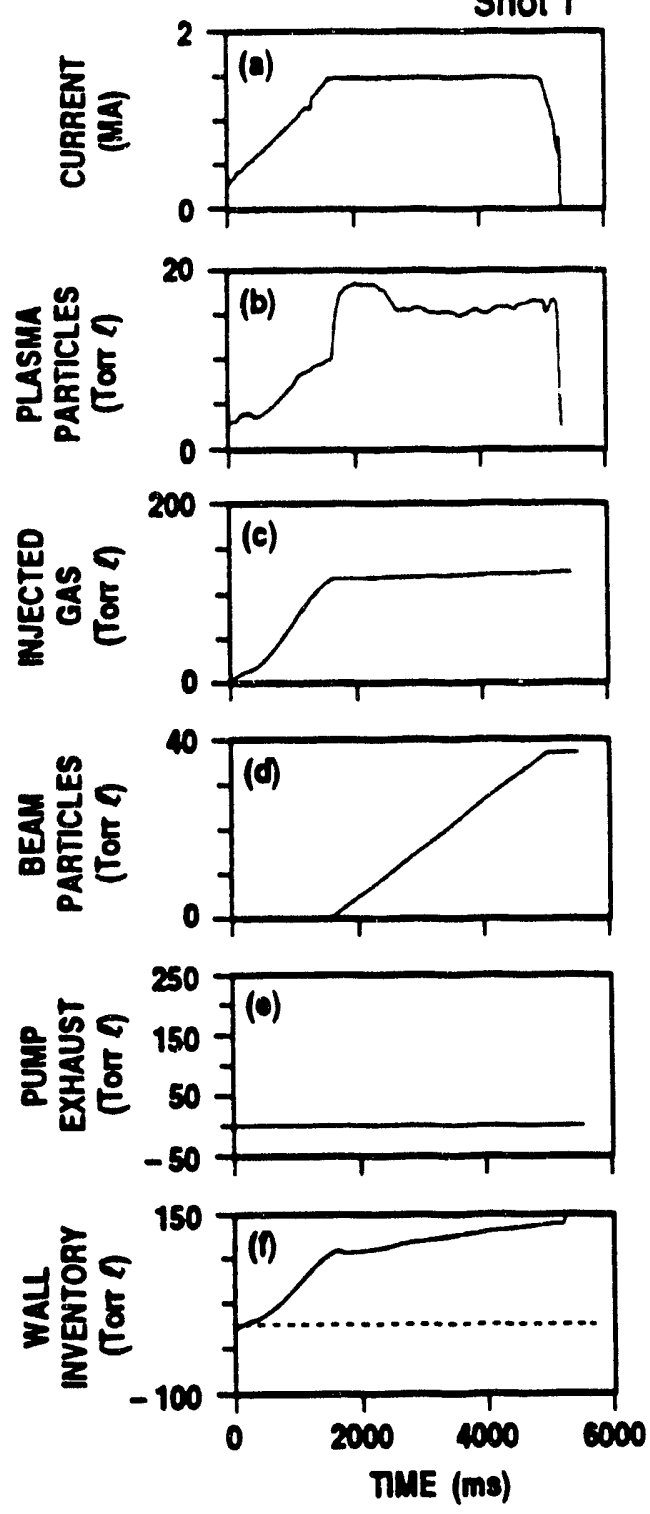

Shot 2
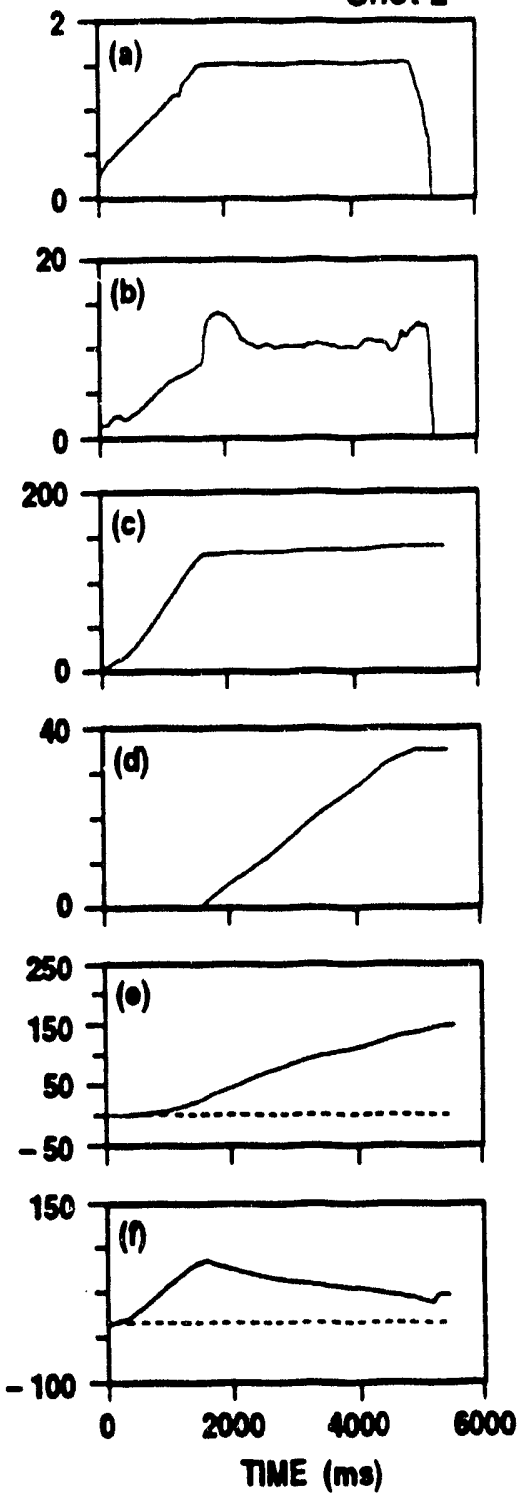

Shot 3
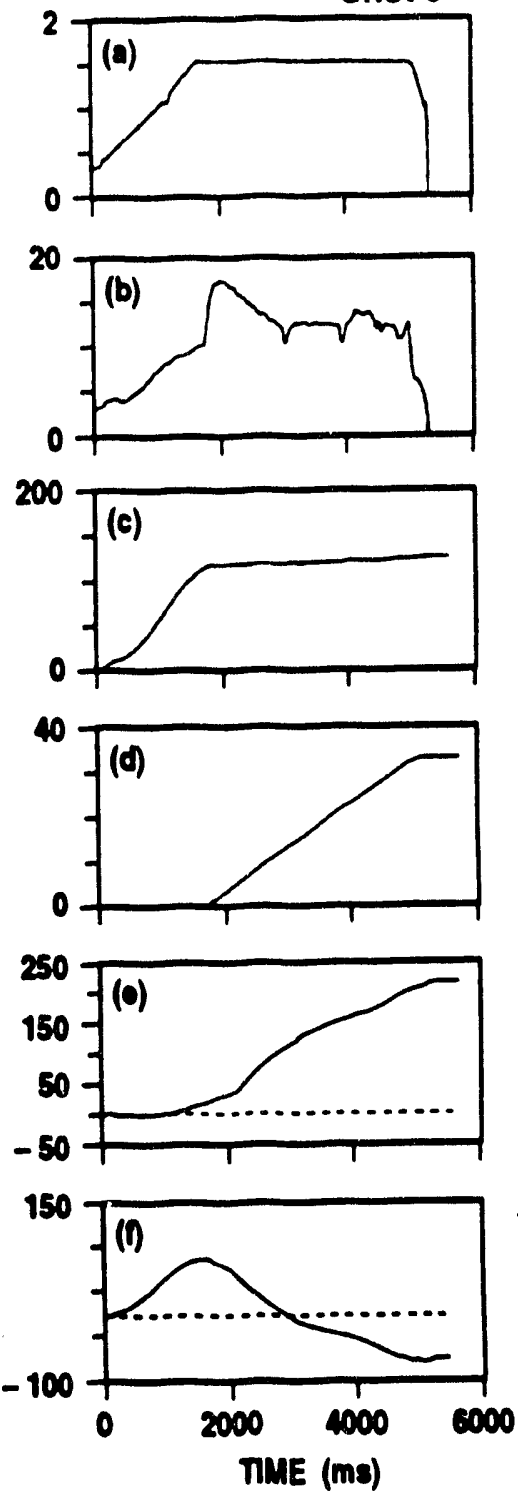

FiG. 5. Comparison of particle balance in pumped and unpumped plasmas. (a) plasms current, (b) particle content of the plasma, (c) injected neutral beam particles, (d) integrated pump exhaust, (e) change in wall particle inventory. Shot 1 - unpumped plasma; except for a brief period after the $L-H$ transition at $t \simeq 1600 \mathrm{~ms}$, wall particle inventory increases continuously throughout the shot. Shot 2 - pumped plasms with pure He glow preceding the plasma shot; after the pump is activated at $t \simeq 1600 \mathrm{~ms}$, wall particle inventory decreases. Shot 3 - pumped plasma with He glow containing some deuterium; at the end of the shot the wall particle inventory is reduced by $\approx 70$ Torr $\ell$.

difference between these two shots is the initial condition of the wall before the plasma shot. In the, former case, the shot was preceded by pure helium glow discharge cleaning whereas in the latter case the glow discharge initially contained some $D_{2}$.

It is important to note that, independently of the initial wall conditions, after $\approx 3$ s of divertor pumping, the pump exhaust rate is approsimately equal to the neutral beam particle source, and as this observation suggests, the initial wall condition does not significantly affect the lowest attainable density of the long pulse plasmas.

\section{DIVERTOR PUMPING EFFECT ON CORE PARAMIETERS}

Divertor pumping modifies the core plasma clensity, temperature, and current profiles. Typically in H-mode plasmas, the profiles evolve for the first two seconds after 
the start of pumping before reaching a quasi steady state. As the plasma density decreases the electron and ion temperatures increase such that the plasma pressure profile remains roughly unchanged. However, in most cases the increase in the central ion temperature is much higher than that of the electron temperature. This difference is explained by the lower energy exchange rate between the plasma ions and electrons at lower density and the fact that, in the parameter range for these plasmas, most of the neutral beam heating power is delivered to the plasma ions.

Fig. 6 shows a comparison of $n_{e}$ and $T_{e}$ profiles of pumped and unpumped shots measured at $t=4.1 \mathrm{~s}, 2.5 \mathrm{~s}$ after the start of pumping. Divertor pumping reduced the electron density gradient and increased the electron temperature gradient just inside the separatrix. Reduced recycling during divertor pumping can explain the change in the density gradient in this region, although a concurrent change in particle transport can not be ruled out. In the core plasma, with $\rho \leq 0.6$, the density gradient is nearly a factor of two higher in the higher density plasma. Since in this region the recycling source is insignificant while the neutral beam particle deposition profile is much broader at the higher density, it follows that particle

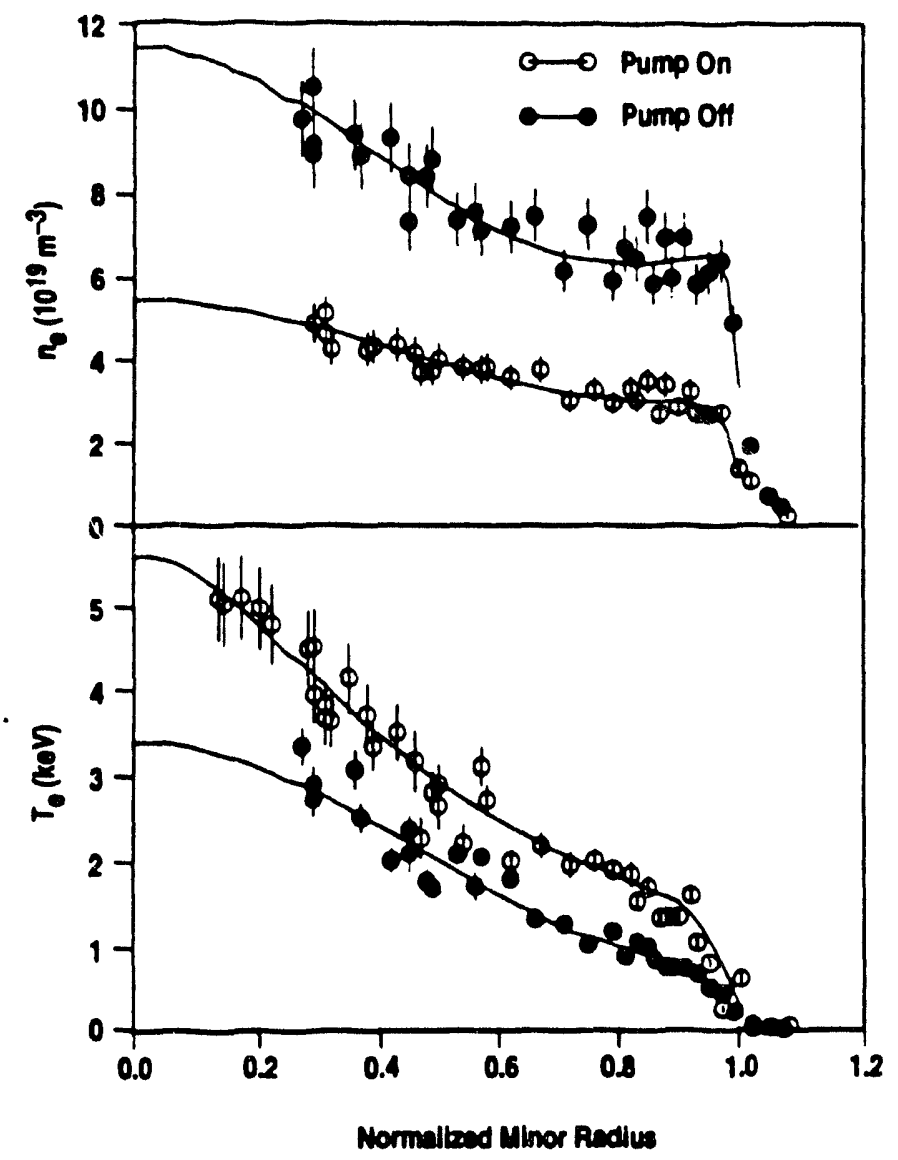

FIG. 6. Electron density and temperature profiles of two otherwise similar $\mathrm{H}$-mode shots with different densities. transport timescale in this region increases nonlinearly with density. We should note that a similar peaking of the density profile was not observed in the low current plasmas.

\section{SUMMARY AND CONCLUSIONS}

We have used an in-vessel cryopump - baffle system to control density of $\mathrm{H}$-mode plasmas. Particle exhaust rates as high as $2 \times 10^{22}$ atom $/ \mathrm{s}^{-1}$ were observed, which exceed ITER requirements. Although an in-vessel cryopump is not a reactor-relevant option, this result demonstrates that in ITER the desired particle exhaust rate can be attained with a modest pumping speed.

We were able to independently regulate plasma current and density of $\mathrm{H}$-mode plasmas, each over a range of factor two. Preliminary analysis shows that the global $\mathrm{H}$-mode confinement time, similar to the I-mode, increases linearly with plasma current and is insensitive to plasma density.

In general, with lower plasma density, the electron and ion temperatures increase such that the plasma pressure profile remains roughly unchanged. However, be cause of a reduced rate of energy transfer from ions to electrons, in most cases the central ion temperature increases much more than the electron temperature.

We have observed evidence of core particle confinement improvement with plasma density. This result sus gests that low density operation may be more favorable for ITER, since for a burning plasms it is necessary that $\tau_{P} / \tau_{E} \lesssim 10$ [21]. Further work is in progress to determine the current and density scaling of the ratio of thermal to particle diffusivity.

\section{ACKNOWLEDGMENT}

The divertor cryopump project is a part of the DIII-D advanced divertor program with participation of GA, LLNL, ORNL, SNL, and UCLA. The authors wish to acknowledge contributions of I. Almajan, P. Anderson, C. Baxi, A. Langhorn, J. Luxon, L. Owen, E. Reis, and L. Sevier to the design of the cryopump and baffle system. We also wish to thank J.C. DeBoo, D.N. Hill, J. Hogan, E.A. Lasarus, W. Obert, M.E. Rensink, and E. Thompson for numerous valuable suggestions and discussions.

\section{REFERENCES}

[1] G.L. Jecteon, T.S. Taylor, S.L. Allen, J.R. Ferron, G. Hasa, D.N. Hill, et al., J. Nual. Mater. 162-164 (1809) pp. 488 405.

[2] M.A. Mahdovi, M.J. Schafer, P. Mioduneewabi, W. Bauer, W. Geunter, G.D. Porter, et al., The DIII-D collaborative advenced divertor progrem," General Atomica Report GAA18547, February 1889.

[3] M.J. Schaffer, S.L. Allen, N.H. Broobe, D. Buchenauer, R.B. Campbell, J.W. Cuthberteca, et al., "Advanoed divertor programme results from DII-D," in Proc. of the 14 th International Conference on Plasma Physics and Controlled Nuclear Furion Research, September 90 through October 7, 1992, Würaburg, Germany, (1803) p. 289. 
[4] C.C. Klepper, J.T. Hogen, D.N. Hill, R. Maingi, L.W. Owen, D. Buchenauer, et al., Nucl. Fuaion 33 (1893) p. 633.

[5] M.A. Mahdavi, M.J. Schuffer, P.M. Anderwon, C.B. Baxi, J.N. Brooke, D. Bucheneuer, et al., Divertor Beffing and Bieaing Experiments on DIII-D," in Proc. of the 19th Interna tional Conference on Plasma Physics and Controlled Nuclear Fusion Research, October 1-6, 1990, Wash ington, D.C., (1901) pp. 335-343.

[6] P.K. Miodunewakd, L.W. Owen, M.M. Menon, and J.T. Hogan, J. Nucl. Mater. 176-177 (1900) p. 733

[7] M.M. Menon, P.M. Anderwon, C.B. Bexi, A. Langharn, J.L. Luxon, M.A. Mahdavi, et al., Funion Tochnol. 22 (1992) pp. 356-370.

(8) L.W. Owen, Bull. AM. Phys. Soc. 34 (1989) p. 2121

[9] M.M. Menon, and P.K. Miodunewewald, "Particle Exhaunt Schemes in the DIII-D Advenced Divertor Configuration," in Proc. of the 19th Symp. on Fusion Engineering, October 2-6, 1989, Knoxville, Tennessee, Val. 1, p. 642.

[10] M.M. Menon, R. Maingi, M.R. Wade, C.B. Baxi, G.L. Campbell, K.L. Holtrop, et al., this conference.

[11] K.M. Schaubel, C.B. Baxi, G.L. Campbell, A.M. Gootgeld, A.R. Langhora, D.G. Laughoa, et al., in Proc. of 14th IEEE/NPSS Symp. on Fusion Engineering, Septem ber 90 through October 3, 1991, San Diego, Califon nia (1892) vol. II, p. 1222.

[12] K.M. Schmubel, G.J. Laughon, G.L. Cempbell, A.R. Lanehorn, N.C. Stevens, and M.L. Tupper, this conference.
[13] C.B. Baxi, P.M. Andernon, A.L. Langharn, K.M. Schaubel, J.P. Smith, in Proc. 2nd International Symp. Fusion Technology (1991).

[14] J.P. Smith, K.M. Schaubel, C.B. Baxi, G.L. Campbell, A.W. Hyatt, A.R. Langhorn, et al., this conference.

[15] E.E. Rein, I. Almajan, C.B. Baxi, M.M. Menon, M.J. Schaffer, D.L. Sevier, and J.P. Smith, in Proc. 17th Symp. on Fusion Technology, September 14-18, 1992, Rome, Italy.

[16] D.G. Laughion, to be publinhed.

[17] K.M. Schaubel, C.B. Baxi, G.L. Campbell, G.J. Laughon, M.A. Mahdevi, M.M. Menon, et al., to be publiehed in Ad vances in Cryogenic Engineering, Vol. $38 .$.

[18] D.P. Schised, private communication.

[19] M.A. Mahdavi, A.G. Kellman, P. Gohil, N.H. Brooka, K.H. Burrell, R.J. Groebser, et al., "Attainment of quadi steadyutate H-mode planmen in the DIII-D tokamak," in Proc. of 16th European Conf. on Controlled Fusion and Plasmas Physics, March 19-17, 1989, Venice, Italy, p. 248.

[20] M.A. Mahdavi, M.J. Schaffer, S.L. Allen, P.M. Anderwon, M.E. Aurtin, C.B. Baxi, et al., "Active denaity control in DIII-D H-mode planmas," in Proc. of 20th European Conf. on Controlled Fusion and Plasma Physics, July 26-30, 1999, Lisbon, Italy (1803) val.II, p.647.

[21] D. Reiter, G.H. Wolf, H. Kever, Nucl. Funion 80, (1889) pp. 2141-2154. 

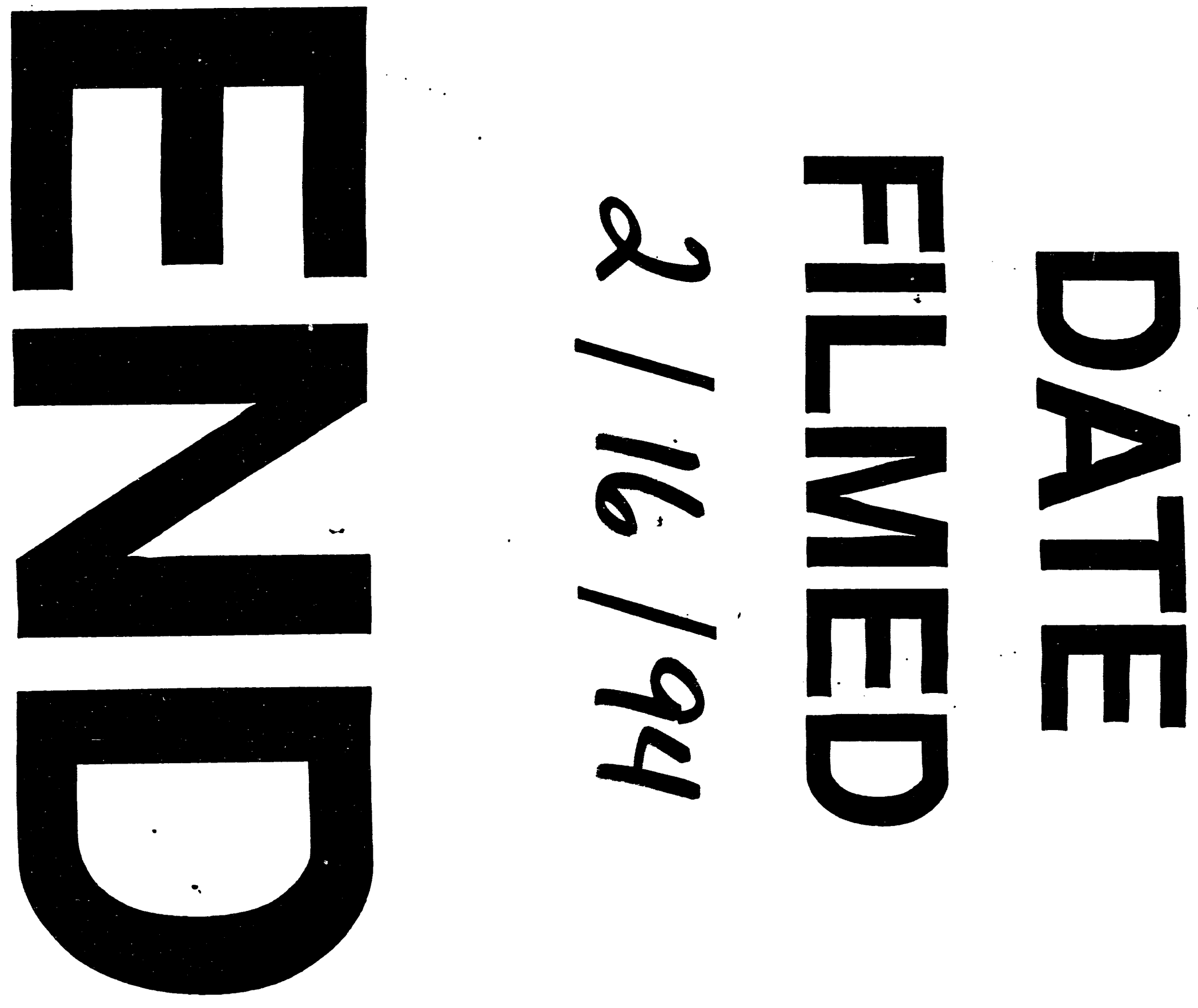
